\title{
The Phythochemical Research of Armenian Apricot Gums (Gummi armeniacae)
}

\author{
Chichoyan Naira Babken ${ }^{1 *}$, Mamyan Suren ${ }^{2}$, Shaboyan Naira ${ }^{3}$, Melikyan Yelena ${ }^{1}$
}

\section{Chichoyan Naira Babken ${ }^{1 *}$, Mamyan Suren², Shaboyan Naira $^{3}$, Melikyan Yelena ${ }^{1}$}

\section{'Department of Pharmacognosy, Yerevan State Medical University after M. Heratsi, Armenia ${ }^{2}$ Molecule Structure Research Center of Institution of the Scientific Technologi- cal Centre of Organic and Pharmaceuti- cal Chemistry of NASRA, Armenia ${ }^{3}$ University of Basel, Faculty of Pharma- ceutical Sciences, Petersplatz 1, 4001 Basel, Switzerland \\ Correspondence}

Dr. Chichoyan Naira Babken

Department of Pharmacognosy, Yerevan State Medical University after M. Heratsi, 2 Koryun str., Yerevan 0025, ARMENIA.

Phone no : 37495626030

E-mail: n.chichoyan@mail.ru

History

- Submission Date: 09-11-2017;

- Review completed: 22-12-2017.

- Accepted Date: 06-01-2018

DOI : 10.5530/pj.2018.3.78

Article Available online

http://www.phcogj.com/v10/i3

\section{Copyright}

(C) 2018 Phcog.Net. This is an openaccess article distributed under the terms of the Creative Commons Attribution 4.0 International license.

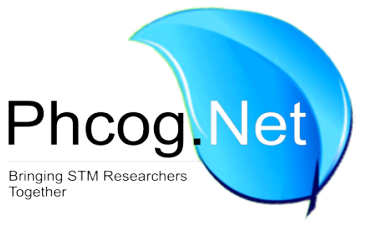

\begin{abstract}
Aim: The plant derivative, the gum's exudates are of great interest among polysaccharides. Nowadays, it is of crucial importance to study the structural peculiarities and the conditioned biological activity of the Gummi Armenicae of native origin as an alternative version of the Gummi Arabicae. Materials and methods: As a material for research served the gum procured from Apricot trees (Armenian Vulgaris Lam.), cultivated in different regions of Armenia annually in spring during juice motion period in 2010-2014 years. The quantity of polysaccharides in gum was determined by the method of gravimetric balance after drying. The quantitative ratio of monosaccharide in the examined polysaccharide complex was detected by the method of MRI. Results: By the methods of spectral analysis (PMR $1 \mathrm{H}$ and NMR 13C) the structure of Apricot gums polysaccharide fraction was detected. From the analysis of PMR $1 \mathrm{H}$ and NMR $13 \mathrm{C}$ spectra it is obvious that polysaccharide complex fraction is composed from the rest of $\alpha$ - L-arabionopyranose, $\beta$-L-arabionopyranose, $\alpha$ - D-galactopyranose, $\beta$-D-galactopyranose, $\alpha$-D-glucopyranose, $\beta$-D-glucopyranose. Low molecular compounds in nonpolar fraction of apricot gum were determined by GC-MS method. The results show that in $\mathrm{Rt} 1=22.5, \mathrm{Rt} 2=26.3, \mathrm{Rt} 3=31.4$. Simple phenols were registered - peaks of catechols hydroquinones, pyrogallols, amounts of which are respectively $7.58 \%, 4.27 \%, 5.69 \%$.

Key words: Apricot gum, Chemical structure, ${ }^{13} \mathrm{C}$ NMR, GC-MS, Simple phenols.
\end{abstract}

\section{INTRODUCTION}

Polysaccharides have important role in the plants, animals and human metabolism. Plant polysaccharides and their modified derivatives are widely used in medicine. Cellulose, hemicellulose, starch, inulin, gum, mucosa and pectin substances are related to the natural plantar polysaccharides or herbal polysaccharides.

It is notable, that previously polysaccharides were applied just as auxiliary substances in different medical preparations manufacturing, meanwhile recently they are observed as biologically active ones. The biologically active plantar polysaccharides are being used in the medical practice for prevention and treatment of diseases of different etiology. Polysaccharides are the potential modifiers of biochemical reactions; they possess emollient, enveloping, immunostimulating, immunomodulating, antitussives, anti-inflammatory, antispasmodic action, antiallergic, antioxidant and antimicrobial activity. ${ }^{1-7}$

The plant derivative, the gum's exudates are of great interest among polysaccharides.

There are some investigations related to different gums of plantar origin, particularly, the (gum Arabic - Acacia Senegal (L.) Willd.), (Guar gum -Cyamopsis tetragonoloba (L.) Taub.), (Mesquite gum- Prosopis chilensis var. velutina (Wooton) Standl.) and others phytochemical research. ${ }^{8,9,10}$
Gums are known at leastfrom the times of Theofrast and (327-287 years B.C) and Dioscorides (I century A. C.). This product, as a remedy in the treatment of a range of diseases, called in Persian and Arabic language as samg or samkh, and in Armenian language as kamed or kroch, was mentioned several times by Persian and Armenian classics of medicine such as Avicenna in his "Canon of Medicine" (X century) and A. Amasiaci in "Angitac anpet".

From practical point of view the most famous gums are Arabic or Senegal Acacia gums (Arabic gums). Being biologically neutral natural polymers and due to their biological ability to form complexes and absorb, Arabic gums are widely used in several spheres of medicine and manufacture as a best replacing agent for gelatin and cellulose. ${ }^{12,13}$

In this point of view the most urgent are the plantar polysaccharides of Armenia's flora considering an increased interest to the local sources all over the world, so it is becoming an issue of great importance. Different gums are known even from the ancient times, information of which is accessible the Persian and Armenian literature sources of Ibn Sina (Avicenna) and Amirdovlat Amasiaci (XV cc). That testifies about the apricot, plum and almond gums use as remedy for treatment of different diseases, including urolithiasis. ${ }^{14,15}$ But having this prehistory 
it did not get its worthy designation in the research aspect after 1960 years, just being an issue of interest in the former Soviet Union times, since it was used for plasma substitution as "Guazolum" during the First Word War. ${ }^{16}$

Nowadays, it is of crucial importance to study the structural peculiarities and the conditioned biological activity of the Gummi Armenicae of native origin as an alternativeversion of the Gummi Arabicae, known as for its significance as effective emulsifier, stabilizer and dietary fiber in medicine and food industry. ${ }^{17,18}$

\section{MATERIALS AND METHODS}

As a material for research served the gum procured from Apricot trees (Armenian Vulgaris Lam.), cultivated in different regions of Armenia annually in spring during juice motion period in 2010-2014 years.

To avoid a tree death, the natural exudates of gums were collected without artificial cut for gum flow. Immediately after collection their primary processing was carried out, cleaning from organic and mineral mixtures, washing and drying. ${ }^{17,18}$

All the samples of raw material were stored in dry, well-ventilated place, in paper bags.

The research was carried out in the Department of Pharmacognosy in YSMU and in the laboratory of «Molecule Structure Research Center NAS RA », Institution of the «Scientific Technological Centre of Organic and Pharmaceutical Chemistry of NAS RA ».

To establish the chemical composition, the collected and dried gum was hydrolized by a sulphuric acid (1:50) $2 \mathrm{M}$ from $30 \mathrm{~min}$ to $24 \mathrm{~h}$ (the hydrolysis was supervised by chromatography). The hydrolizate was neutralized, sedimented and refiltered. The ratio of filtered monosaccharides (1:3) were detected with the help of $95 \%$ alcohol. Neutral monosaccharides that passed into the filtrate were densified by rotor till the formation of dry definite mass.

The quantity of polysaccharides in gum was determined by the method of gravimetric balance after drying. The quantitative ratio of monosaccharide in the examined polysaccharide complex was detected by the method of MRI. The ranges of a nuclear magnetic resonance ${ }^{1} \mathrm{H}$ and ${ }^{13} \mathrm{C}$ took out on the Varian-Mercury device - 300VX (300 MHz) in D2O solution $(99,9 \%)$ at $30{ }^{\circ} \mathrm{C}$ (the internal standard - an acetone; $\delta \mathrm{H} \mathrm{2,225}$ $\mathrm{m}$ of, $\delta \mathrm{C} 31.45 \mathrm{~m})$.

Low molecular compounds in non-polar fraction of Apricot tree's gum were determined by the gas chromatography- mass spectrometry (GC-MS) method on gas chromatograph with mass selective spectrometer from BRUKER Company (USA). An OPTIMA-FFAP capillary column (0.25 mkm, $60 \mathrm{~m}^{\star} 0.25 \mathrm{~mm}$ (ID, MACHEREY-NAGEL, Germany) was used for the separation of volatile oil compounds. Helium gas carrier had flow-rate $1.0 \mathrm{ml} / \mathrm{min}$, volume of injected sample $2 \mathrm{mkl}$, the oven temperature was $220 \mathrm{C}$, temperature gradient $50 \mathrm{C}$ ( $2 \mathrm{~min}$ ), split-separation -5. Compounds were identified using the NIST Mass spectral Search Program.

The content of components was calculated by GC peak's area, without correction factors. Identification of components was carried out by their retention times. Quantitative analysis of components was determined by internal normalization method.

\section{RESULTS AND DISCUSSION}

\section{Spectral Analysis}

The chemical shifts of pyranosyl monosaccharides were also detected in the laboratory of the $<<$ Molecule Structure Research Center NAS RA $>>$ Institute of the $<<$ Scientific Technological Centre of Organic and Pharmaceutical Chemistry of NAS RA $>>$.
The ranges of a nuclear magnetic resonance ${ }^{1} \mathrm{H}$ and ${ }^{13} \mathrm{C}$ took out on the Varian-Mercury device - 300VX (300 MHz) in D2O solution (99,9\%)

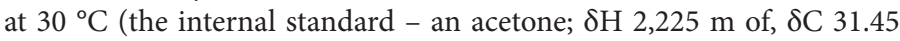
$\mathrm{m}$ of). The first sample of mixture contained approximately: $35 \%$ $\beta$-L-arabinopyranoses and $65 \% \alpha$-L- arabinopyranoses (H1- $\beta 5.22, \mathrm{~d}$, 3J_3,5Hz, H1- $\alpha$ 4.50, d, 3J_7,8Hz, H2- $\alpha 3.50, \mathrm{dd}, 3 \mathrm{~J}=7,8 \mathrm{~Hz}, 3 \mathrm{~J}=9,8 \mathrm{~Hz}$, 3.60-4.14, m, 9 H; C1- 9 97.9, C2- - 73.0, C3- $\alpha$ 73.6, C4- $\alpha$ 69.6, C5- $\alpha$ 67.5, C1- $\beta$ 93.7,C2- $\beta$ 69.6, C3- $\beta$ 69.8, C4- $\beta$ 69.8, C5- $\beta$ 63.6). (Figure 1)

The second sample of mixture was approximately of: $50 \% \quad \alpha-D$ galactopyranoses and $50 \% \beta$-D-galactopyranoses $(\mathrm{H} 1-\alpha 5.27, \mathrm{~d}, 3 \mathrm{~J}=3,5 \mathrm{~Hz}$, $\mathrm{H} 1-\beta 4.59, \mathrm{~d}, 3 \mathrm{~J}=7,8 \mathrm{~Hz}, \mathrm{H} 2-\beta 3.49$, dd, 3J_7,8Hz, 3J_9,9Hz, 3.62-4.12, m, $11 \mathrm{H}$; C1- $\alpha$ 93.6, C2- $\alpha$ 69.7, C3- $\alpha$ 70.5, C4- $\alpha$ 70.6, C5- $\alpha$ 71.8, C6- $\alpha$ 62.5,

C1- $\beta$ 97.8, C2- $\beta$ 73.2, C3- $\beta$ 74.1, C4- $\beta$ 70.1, C5- $\beta$ 76.5, C6- $\beta$ 62.3). (Figure 2 ) The third sample of mixture was approximately of: $70 \% \alpha-\mathrm{D}$ glucopyranoses and 30\% $\beta$-D-glucopyranoses (H1- $\alpha$ 5.23, d, 3J_3,7Hz, $\mathrm{H} 1-\beta 4.64, \mathrm{~d}, 3 \mathrm{~J}=7,9 \mathrm{~Hz}, \mathrm{H} 2-\beta 3.24$, dd, 3J_7,9Hz, 3J_9,3Hz, 3.36-3.56, m, 4 H, 3.68-3.93, m, 7H; C1- $\alpha$ 92.7, C2- $\alpha$ 72.1, C3- $\alpha$ 73.4, C4- $\alpha$ 70.6, C5- $\alpha$ 72.1, C6- $\alpha$ 61.2, C1- $\beta$ 96.5, C2- $\beta 74.8$, C3- $\beta$ 76.4, C4- $\beta$ 70.2, C5- $\beta$ 76.6, C6- $\beta$ 61.4). (Figure 3)

From the ${ }^{1} \mathrm{H}$ and ${ }^{13} \mathrm{C}$ nuclear magnetic resonance analysis the following ranges of polysaccharide complex fractions consisting of the remnants of $\beta$-L-arabinopyranoses and $\alpha$-L-arabinopyranoses, $\alpha$-D-galactopyranoses

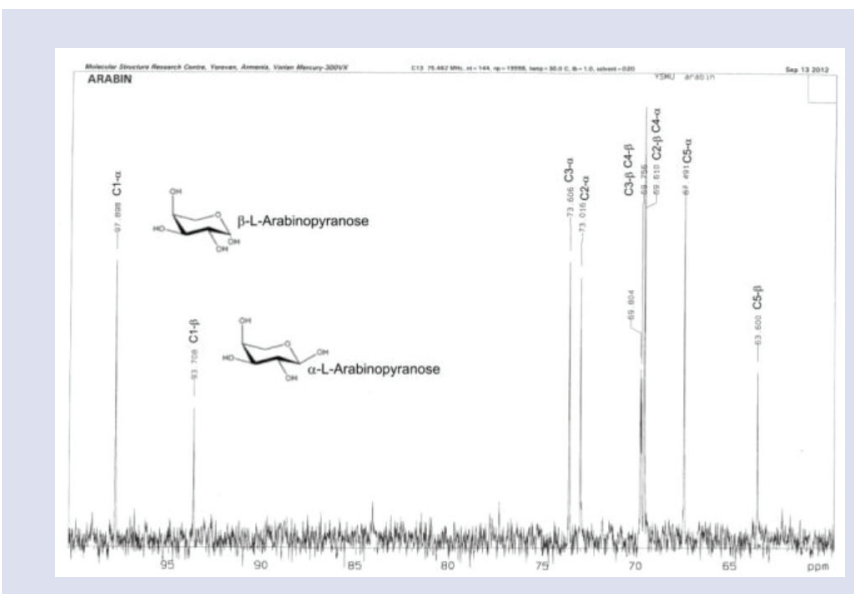

Figure 1: ${ }^{13} \mathrm{C}$ NMR analysis of polysaccharide complex $-\beta-\mathrm{L}-$ arabinopyranoses and $\mathrm{a}-\mathrm{L}$ - arabinopyranoses.

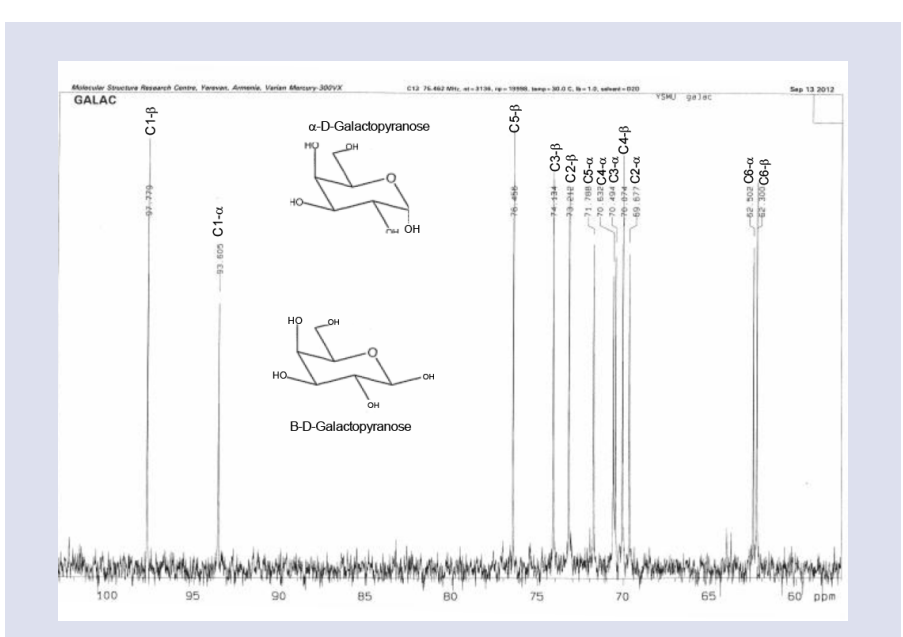

Figure 2: ${ }^{13} \mathrm{C}$ NMR analysis of polysaccharide complex - $\mathrm{a}-\mathrm{D}$ galactopyranoses and $\beta$-D-galactopyranoses. 


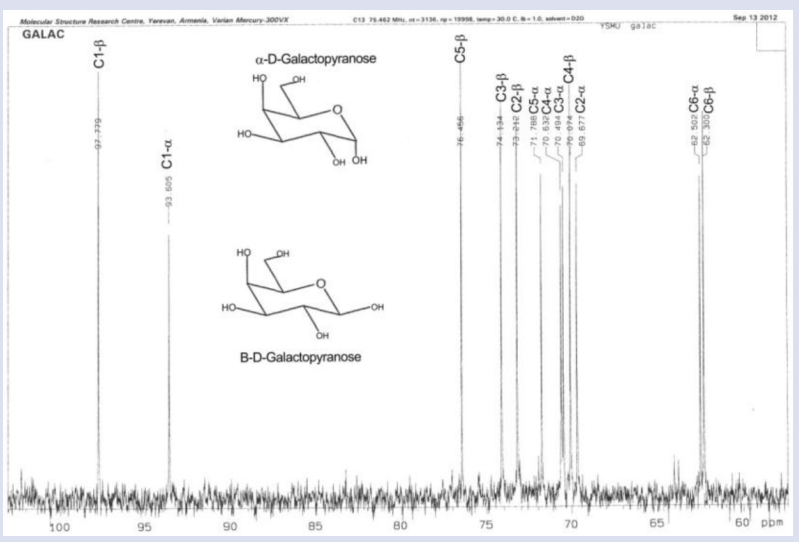

Figure $3:{ }^{13} \mathrm{C}$ NMR analysis of the polysaccharide complex - $\mathrm{a}-\mathrm{D}-$ glucopyranoses and $\beta$-D-glucopyranoses.

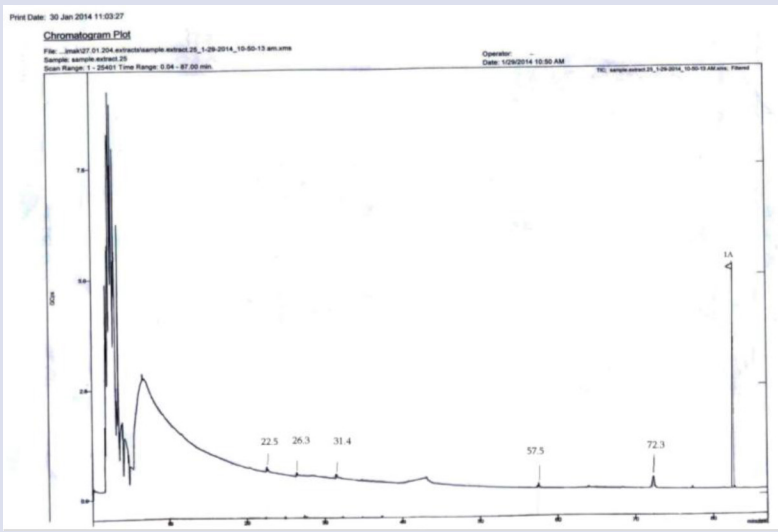

Figure 4: Peacks of low molecular components of native apricot gum on chromatograms (GC-MS method). 1-catechol (1, 2- dihydroxybenzole), $\mathrm{Rt}_{1}=22.5,2$-hydroquinone (1.4- dihydroxybenzole), $\mathrm{Rt}_{2}=26.3$, 3- pyrogalluol(1,2,3- trihydroxybenzole) $\mathrm{Rt}_{3}=31.4$.

and $\beta$-D-galactopyranoses, $\alpha$-D-glucopyranoses and $\beta$-D-glucopyranoses were detected.

\section{GC-MS Analysis}

Quality analysis of low molecular components, carried out by comparison of retention times of gum components, mass-specters of containing substances and pure substances in samples with NIST mass spectral search Program data, showed that in parallel with basic polysaccharide fraction also compounds of phenol origin exist in apricot gum.

The later, as is known, participate actively in metabolic processes taking place in wood and core. Consequently, they immediately get involved in gum production process during the modification of their cell membranes. The results on chromatograms show, that at retention times $\mathrm{Rt}_{1}=22.5$, $\mathrm{Rt}_{2}=26.3, \mathrm{Rt}_{3}=31.4$, simple phenols are registered-peaks of catechols, hydroquinones, pyrogalluol, amount of which are respectively $7.58 \%$, $4.27 \%$ and $5.69 \%$ (Figure 4 ).

The presence of non-polar (low molecular) compounds shows the direct participation of cambial layer of core in gum formation process.

\section{CONCLUSION}

By the methods of spectral analysis (PMR ${ }^{1} \mathrm{H}$ and $\left.\mathrm{NMR}{ }^{13} \mathrm{C}\right)$ the structure of Apricot gums polysaccharide fraction was detected. From the analysis of PMR ${ }^{1} \mathrm{H}$ and NMR ${ }^{13} \mathrm{C}$ spectra it is obvious that polysaccharide complex fraction is composed from the rest of $\alpha$ - $\mathrm{L}$-arabionopyranose, $\beta$-L-arabionopyranose, $\alpha$ - D-galactopyranose, $\beta$-D-galactopyranose, $\alpha$-D-glucopyranose, $\beta$-D-glucopyranose.

Low molecular compounds in nonpolar fraction of apricot gum were determined by GC-MS method. The results show that in $\mathrm{Rt}_{1}=22.5$, $\mathrm{Rt}_{2}=26.3, \mathrm{Rt}_{3}=31.4$. Simple phenols were registered - peaks of catechols hydroquinones, pyrogallols, amounds of which are respectively $7.58 \%$, $4.27 \%, 5.69 \%$.

\section{ACKNOWLEDGEMENT}

This research was carried out by support of the Scientific Agency of YSMU of Armenia.

\section{CONFLICT OF INTEREST}

The authors declare no conflict of interest.

\section{ABBREVIATIONS USED}

NMR: Nuclear magnetic resonance; PMR: Proton magnetic resonance; MRI: Magnetic resonance imaging; GC: Gas chromatography; GC-MS: Gas chromatography- mass spectrometry.

\section{REFERENCES}

1. Babeshina LG, Gorina YV, Kolokolava AP, Krasnov EA, Karpov MR. The study on some types of polysaccharide sorts Sphagnum L. Journal of Siberian Federal University. Chemistry. 2010;413-10.

2. Krishtanova NA, Safonov MJ, et al. The prospects of the use of herbal polysaccharides as healing and preventive preparations. Pharmacy. 2005;212-21.

3. Chen HL1, Li DF, Chang BY, Gong LM, Dai JG, Yi GF. Effects of Chinese herbal polysaccharides on the immunity and growth performance of young broilers. Poult Sci. 2003;82(3):364-70.

4. Han J1, Bian L1, Liu X1, Zhang F1, Zhang Y1, Yu N1. Effects of Acanthopanax senticosus Polysaccharide Supplementations on Growth Performance, Immunity, Blood Parameters and Expression of Pro-Inflammatory Cytokines Genes in Challenged Weaned Piglets. Asian-Australas J Anim Sci. 2014;27(7):1035-43. doi: 10.5713/ajas.2013.13659

5. Nosalovaa G, Fleskovaa D, Jureceka L, Sadlonovaa V, Rayb B. Herbal polysaccharides and cough reflex. Respiratory Physiology and Neurobiology. 2013;187(1):47-51.

6. Matouskova Z, Marova I, Bokrova J, Benesova P. Effect of Encapsulation on Antimicrobial Activity of Herbal Extracts with Lysozyme. Food Technology and Biotechnology. 2016;54(3):304.

7. Chichoyan NB, Natural raw material resources of apricot gums of republic Armenia and perspectives of their use. Actual problems of Botany in Armenia. Materials of international conference. Inst of Botany NAS RA. Yerevan. 2008;307-10.

8. López-Franco YL, Córdova-Moreno RE, Goycoolea FM, Valdez MA, JuárezOnofre J, Lizardi-Mendoza J. Classification and physicochemical characterization of mesquite gum Prosopis spp. Food Hydrocolloids. 2012;26(1):159-66.

9. Elmanan M, Al-Assaf S, Phillips GO, Williams PA. Studies on Acacia exudate gums: Part VI. Interfacial rheology of Acacia senegal and Acacia seyal. Food Hydrocolloids. 2008;22(4):682-9.

10. Verbecen D, Dierckx S, Dewettinck K. Exudate gums: occurrence, production, and applications. Appl. Microbiol. Biotechnol. 2003;63(1):10-21.

11. Revazova LV, Chichoyan NB, Melikyan YA. The usage of gums in medieval Armenian medicine and modern aspects of their usage. Collection "Depon. Nauch Raboti". 1996;3:12

12. McNamee BF, O'Roirdann ED. «Emulsification and Microcapsulation Properties of gum arabic». J Agric Food Chem. 1998;64(11):4551-5.

13. El-Kheir MK, Abu El Gasim AY, Baker Abu A. Emulsion-stabilizing effect of gum from Acacia Senegal (L) Willd. the role of quality and grade of gum, oil type, temperature,stirring time and concentration. Pak J Nutr. 2008;7(3):395-9.

14. Amasiatsi A, Useless for ignoramuses. "Nauka" press; Moscow. 1990.

15. Abu Ali ibn Sina (Avicenna), The Canon of Medicine. Book II, Ed. Tashkent, Uzbek Academy of Sciences. 1956.

16. Umansky ZM, Olyshansky MI, Frimerman ML. Colloid - saline (guazol). Pharma- 
cology and Toxicology. 1946;2:63-2.

17. Chichoyan NB, Pharmacognostic studies of gums collected from apricot trees growing in Armenia and perspectives of their use. Georgian Medical News.
2009;1(176): 74-4.

18. Chichoyan NB, Gummi Armeniacae collected from Apricot trees in Armenia- perspective source of arabinigalactan. Georgian Medical News. 2011;3(192):92-5.

\section{SUMMARY}

- Nowadays, it is of crucial importance to study the structural peculiarities and the conditioned biological activity of the Gummi Armenicae of native origin as an alternative version of the Gummi arabicae. The research materials were gums harvested from the Apricot trees cultivating in several regions of RA. The quantity of polysaccharides in gum was determined by the method of gravimetric balance after drying. The quantitative ratio of monosaccharide in the examined polysaccharide complex was detected by the method of MRI. By the methods of spectral analysis (PMR $\left.{ }_{1} \mathrm{H}_{\text {and }} \mathrm{NMR}{ }_{13} \mathrm{C}\right)$ the structure of Apricot gums polysaccharide fraction was detected. From the analysis of PMR ${ }_{1} \mathrm{H}$ and NMR ${ }_{13} \mathrm{C}$ spectra it is obvious that polysaccharide complex fraction is composed from the rest of $\alpha$ - L-arabionopyranose, $\beta$-L-arabionopyranose, $\alpha$ - D-galactopyranose, $\beta$-D-galactopyranose, $\alpha$-D-glucopyranose, $\beta$-D-glucopyranose. Low molecular compounds in nonpolar fraction of apricot gum were determined by GC-MS method. The results show that in $\mathrm{Rt}_{1}=22.5, \mathrm{Rt}_{2}=26.3, \mathrm{Rt}_{3}=31.4$. Simple phenols were registered - peaks of catechols' hydroquinones, pyrogallols, amounts of which are respectively $7.58 \%, 4.27 \%, 5.69 \%$.

Cite this article: Chichoyan N, Mamyan S, Shaboyan N, Melikyan Y. The Phythochemical Research of Armenian Apricot Gums (Gummi armeniacae). Pharmacog J. 2018;10(3):476-79. 